\title{
SISTEMA SUPERVISÓRIO PARA TANQUES DE COMBUSTÍVEIS SUBTERRÂNEOS
}

\author{
Miguel Natalucci de Lemos \\ Estudante de Engenharia de Produção na Unisuam, Rio de Janeiro, RJ, Brasil. \\ miguelnatalucci@gmail.com \\ Ana Carolina Pereira Sant' Anna \\ Estudante de Engenharia de Produção na Unisuam, Rio de Janeiro, RJ, Brasil. \\ carolina_santanna@hotmail.com \\ Pedro Paulo Sena Passos \\ Professor orientador, Unisuam, Rio de Janeiro, RJ, Brasil. \\ pedro.sena@souunisuam.com.br
}

\begin{abstract}
Resumo
O presente artigo aborda a criação de um sistema eletrônico que se conecta a qualquer dispositivo móvel, a fim de tendo em vista realizar o monitoramento do nível de combustíveis armazenados em tanques de combustíveis subterrâneos. Neste trabalho também são apresentados vantagens em relação a métodos de medição atuais; relacionando custo-benefício e confiabilidade do material a ser utilizado, comprovando a possibilidade de inserir em um estabelecimento comercial um sistema de baixo custo e com precisão elevada.
\end{abstract}

Palavras-chave: Sistema eletrônico. Tanques Subterrâneos. Nível de combustível. Medição.

\section{SUPERVISORY SYSTEM FOR UNDERGROUND FUEL TANKS.}

\begin{abstract}
This article addresses the creation of an electronic system that connects to any mobile device in order to monitor the level of fuel stored in underground fuel tanks. In this work, advantages are also presented in relation to current measurement methods; relating cost-benefit and reliability of the material to be used, proving the possibility of inserting in a commercial establishment a system of low cost and with high precision.
\end{abstract}

Keywords: Electronic system. Underground tanks. Level of fuel. Measurement.

\section{INTRODUÇÃO}

O ano de 2017 apresentou um aumento no número de veículos de cerca de 1,2\% em relação a 2016. Este percentual parece pouco, mas representa um aumento de aproximadamente 3,371 milhões de automóveis ${ }^{1}$. O crescimento registrado no último ano; este aumento resulta em um

\footnotetext{
${ }^{1}$ https://g1.globo.com/carros/noticia/frota-brasileira-de-veiculos-cresce-12-em-2017-diz-sindipecas.ghtml
} 
decréscimo mais rápido da quantidade de combustível disponível nos postos, o que exige mais atenção ao nível dos tanques subterrâneos por parte dos proprietários destes estabelecimentos.

Para realizar o controle do nível dos tanques em que são armazenados os combustíveis existem alguns métodos capazes de mensurar a quantidade atual, porém alguns não muito precisos, e outros nem tão acessíveis. Pensando na relação custo-benefício, foi desenvolvido um sistema eletrônico capaz de realizar tal medição.

\section{METODOLOGIA}

A tarefa de monitorar o volume de combustível em tanques de postos de abastecimentos é tradicionalmente realizada de forma manual (regulamentada pela NBR 13787/2013); utilizando uma régua de medição. Durante a medição, a régua é inserida no tanque e após retirá-la, o funcionário e verifica em que ponto da escala da régua encontra-se o nível do produto. Ainda é necessário utilizar uma tabela de conversão para obter o volume em litros, correspondente ao indicado na escala da régua. Este método pode gerar marcações imprecisas, pois a verificação do nível depende única e exclusivamente do manuseio da régua pelo funcionário. Um simples balançar ao segurar a régua já é suficiente para distorcer, ao menos o mínimo, a marcação. Toda medição realizada está sujeita a erros observacionais, por parte do operador. Além da margem de erro que a tabela de conversão também possui; de $2,5 \%^{2}$

Para que se possa ter uma ideia; levando em conta as informações de uma tabela para medição de tanques, um erro de 1 centímetro na medição de um tanque de 30.000 litros, por exemplo, reflete uma diferença de cerca de 120 litros de combustível. Esta margem de erro, que aparenta ser pequena por equivaler somente $0,4 \%$ do total do tanque, é o suficiente para representar prejuízo ao proprietário do posto.

\subsection{Apoio financeiro}

Ao acessar a área de consulta de revendedores de combustíveis ainda em operação no país (na página oficial da ANP (Agência Nacional do Petróleo)) é possível constatar que o Brasil já conta com mais de 40.000 postos de combustíveis, e deste total quase metade (18.519) são postos denominados bandeira branca, ou seja; estabelecimentos que não recebem apoio financeiro de

\footnotetext{
${ }^{2}$ http://www.arxo.com/arquivos/portal/53-tanque-arxo-subterraneo-jaquetado-horizontal-pleno-30-000l.pdf
} 
empresas de distribuição de combustíveis, o que dificulta ainda mais a possibilidade de investimento em modernização do sistema de medição.

\subsection{Sugestão de um novo sistema}

Pensando na modernização dos reservatórios, mas sem a necessidade de realizar sua substituição, foi elaborado um protótipo, para o qual foi estudada a utilização de sensores de nível construídos de material plástico não corrosivo. Os sensores estarão conectados em série, em um suporte feito de material PVC, que por sua vez será acoplado na tampa do reservatório, como mostra a imagem do protótipo desenvolvido, visando substituir a régua de medição.

Figura 1 - Imagem do protótipo desenvolvido (Fonte: Próprios autores, 2018)

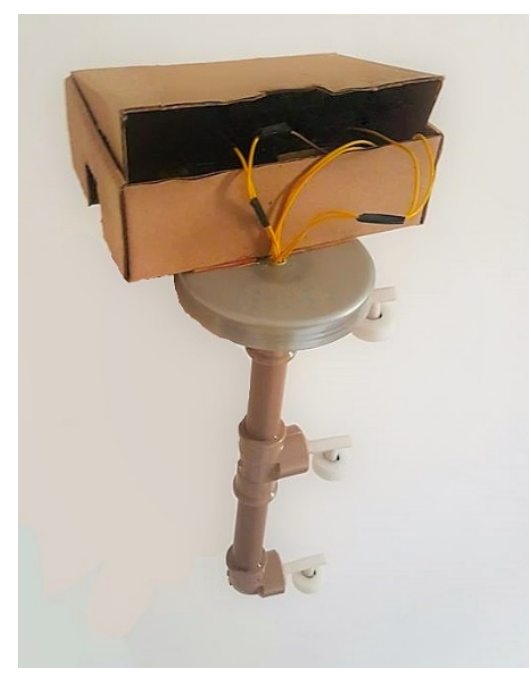

Este sistema eleva a confiabilidade da medição, pois elimina por completo a probabilidade de erros observacionais, e torna a medição mais prática, pois com o dispositivo fixado na parte interna da tampa do tanque, não há necessidade de abri-la para aferir. Isto suprime todo o risco de exposição do produto durante o processo de medição.

\section{RESULTADOS E DISCUSSÕES}

Além da simplicidade do dispositivo e sua confiabilidade, o sistema desenvolvido oferece outra vantagem em relação às réguas de medição: a implantação de maneira permanente ou móvel (removível). No caso da aplicação móvel; será realizada a inserção no tanque, ao lugar da régua, e após interpretar o resultado o dispositivo é retirado. 
A geração do resultado da medição fica a cargo da placa controladora denominada Arduino, como mostra a figura abaixo. Esta interpretará os sinais emitidos pelos sensores, encaminhando os dados obtidos, via Bluetooth para qualquer dispositivo móvel conectado ao sistema (celular, tablet, computador de mesa, ou notebook), exibindo através do aplicativo, o nível do tanque com precisão e em tempo real. O sistema utiliza de alimentação de 3,3V a $20 \mathrm{~V}$, porém com valor recomendado de $5 \mathrm{~V}$ a $12 \mathrm{~V}$.

Figura 2 - Esquemático básico de ligações, com sensores, placa controladora Arduino e módulo bluetooth.

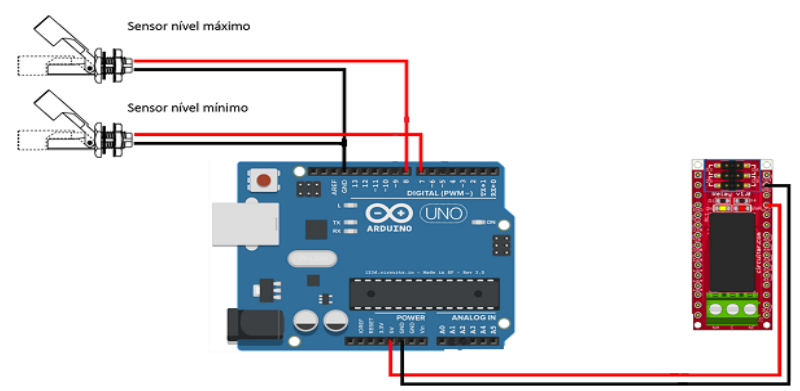

Fonte: (Autores, 2017)

Outra vantagem é a visualização imediata do resultado da medição, através do aplicativo citado, e enquanto ao uso da régua se torna necessária a tabela de conversão para que se obtenha um valor aproximado, com o sistema projetado dispensa seu uso.

Figura 3 - Telas da aplicação executada em dispositivo móvel: Tela de início, Monitor, Chamada Telefônica e Tela de Relatórios; respectivamente.

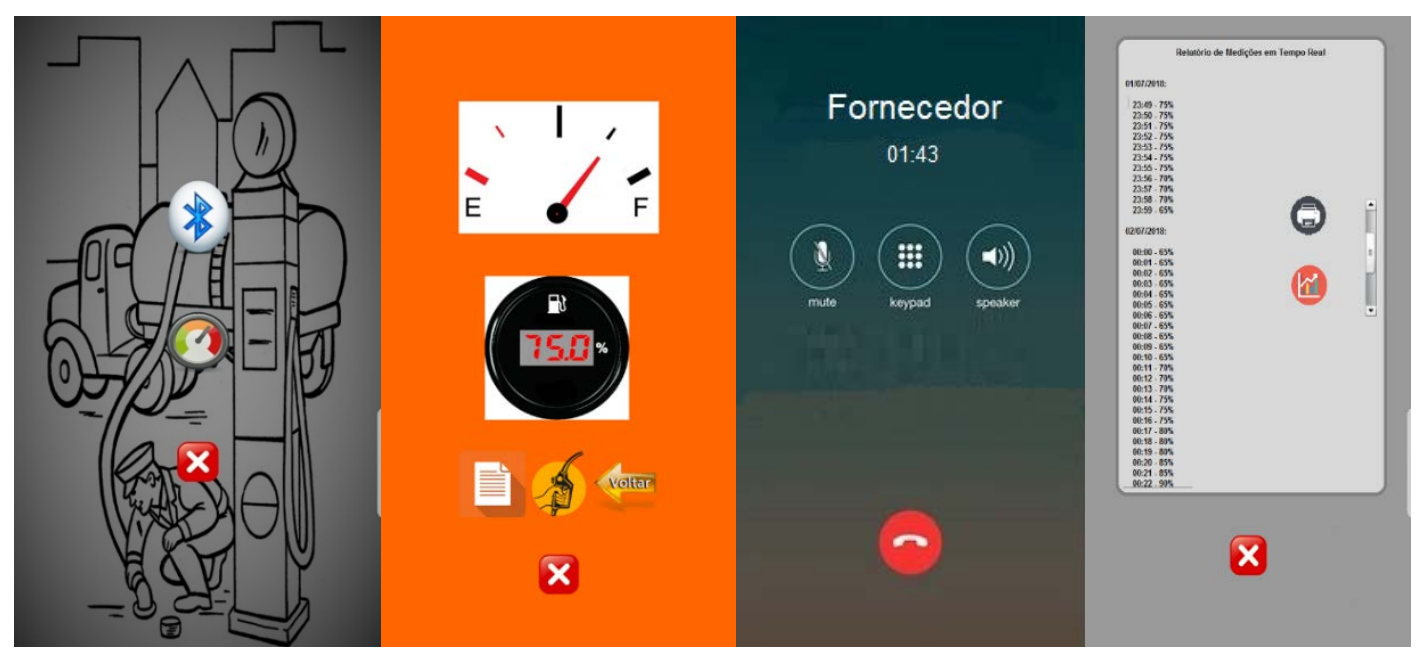

Fonte: (Autores, 2017) 
$\mathrm{Na}$ tela inicial da aplicação é possível ativar/interromper a conexão Bluetooth entre o sistema e o dispositivo móvel. Também é exibido o botão para acesso à tela de resultados das medições, em tempo real; realizadas com intervalos programados de 1 segundo entre uma medição e outra. Nesta mesma tela há um botão centralizado que, ao sofrer um clique, direciona o usuário ao site do fornecedor de combustível, e ao mantê-lo pressionado, caso utilize um aparelho celular, efetua-se uma chamada para o número da distribuidora contratada pelo estabelecimento.

Já na janela de relatórios é possível visualizar, minuto a minuto, os resultados das medições. Sendo possível encaminhar o relatório para impressão; contendo estes resultados e as médias de consumo por período. O botão vermelho sinalizado na última figura, abaixo do botão para imprimir, destina-se a uma nova tela, ainda em desenvolvimento, cuja a funcionalidade é converter os resultados descritos acima em uma exibição em gráficos.

\subsection{Medidas de segurança}

A placa controladora do sistema localiza-se do lado de fora do tanque subterrâneo, podendo ser alimentada por tomada, baterias de íon lítio, pilhas, ou pelo próprio computador; através de uma entrada USB. A baixa tensão, a qual o dispositivo trabalha, e a localização e isolamento de seus componentes, evitam o risco de qualquer ignição que possa provocar uma possível explosão. E ela pode ser instalada em qualquer localidade do estabelecimento.

Esta placa interliga-se ao suporte em PVC mergulhado ao tanque, que abriga os cabos que realizam a conexão dos sensores com a placa controladora. Como o sistema fornece a medição em tempo real, o proprietário poderá facilmente identificar furtos de combustíveis, que ocorram durante a inatividade do estabelecimento.

\subsubsection{Antecipação da detecção de vazamentos}

A NBR 13784 estabelece a obrigatoriedade da adoção de métodos de detecção de vazamentos em sistemas de armazenamento subterrâneos de combustíveis, visando evitar contaminação de aquíferos, solo ou ar. Por padrão, os tanques atuais possuem um mecanismo que detecta vazamentos; geralmente sensores localizados em pontos estratégicos do tanque que notificam a ocorrência de vazamento apenas após uma quantidade determinada de combustível ter sido identificada pelos sensores. Pensando nisto foi implementado ao sistema um procedimento de antecipação da deteç̧ão de vazamentos, que funciona da seguinte forma: o sistema monitora o 
nível do tanque e nestas constantes medições disponibiliza, em intervalos programados de tempo, as estatísticas das medições.

Há um limite programado de possível variação do nível do tanque enquanto o mesmo não é utilizado, pois fatores externos como a temperatura podem influenciar no material do tanque e na composição do combustível líquido, fazendo com que os sensores afiram uma medição errônea, contudo dentro da margem de erro prevista. Este limite foi definido levando em conta o sinal emitido pelos sensores, que somente acionará o sistema se a variação for superior a 0,02\%, que representa em um tanque de 30.000 litros, por exemplo, a quantidade de 6 litros.

Em caso de decréscimo superior ao limite serão disparadas mensagens de alerta sobre a possibilidade de vazamento. Este procedimento disponibiliza mais tempo hábil para que se possa realizar uma melhor verificação e executar, caso necessário, a manutenção corretiva necessária ao bom funcionamento do tanque. Vale ratificar que o sistema supervisório em questão foi desenvolvido totalmente em conformidade com as leis de proteção ao meio ambiente, normas ABNT e portarias do INMETRO.

\subsection{Sustentabilidade Ambiental}

Tanto funcionários dos postos, como também os clientes, estão expostos a uma série de riscos por inalar quantidades de vapor de gasolina, que contém um hidrocarboneto aromático chamado benzeno. O benzeno, presente na composição da gasolina, é considerado nocivo à saúde, altamente cancerígeno. O Anexo no 2 da NR 9, intitulado Exposição Ocupacional ao Benzeno em Postos Revendedores de Combustíveis, traz algumas exigências para os postos de combustíveis. Através do conhecimento das normas vigentes e do estudo das consequências da contaminação por benzeno, foi desenvolvido um sistema capaz de auxiliar na identificação de vazamentos. Como citado anteriormente, o sistema dispões de um procedimento de antecipação da detecção de vazamentos, que visa reduzir as chances de contaminação do lençol freático.

O item 14 do Anexo n 2 da NR9 reserva a obrigatoriedade de instalação de um sistema de recuperação de vapor de gasolina, definindo que deve ser instalado nos bicos de abastecimento das bombas, direcionando os vapores para o próprio tanque subterrâneo ou para um equipamento de tratamento de vapores. Os estabelecimentos terão o prazo de até o dia 21 de Setembro de 2019 para instalarem o sistema em questão ${ }^{3}$. Portanto, um posto que implantar este equipamento de

\footnotetext{
${ }^{3}$ http://trabalho.gov.br/images/Documentos/SST/NR/NR09/NR-09-2016.pdf
} 
recuperação de vapores, juntamente a utilização do sistema supervisório abordado neste artigo, elimina em $100 \%$ as chances de exposição direta do ser humano ao benzeno, já que a substância não mais será liberada através dos bicos das bombas, e nem através da tampa do reservatório durante a medição.

\subsection{Sustentabilidade Econômica}

Para maximizar a previsão do retorno financeiro esperado, os proprietários devem possuir um eficiente controle sobre o estoque de combustível. Do contrário, a administração financeira da empresa é prejudicada. Monitorando o nível do tanque utilizando este novo sistema, a empresa consegue uma melhor programação de abastecimento, por seus fornecedores, potencializando a gestão logística da empresa.

Em uma situação de vazamento, por exemplo, detectar rapidamente a possibilidade de este evento ocorrer economiza tempo e consequentemente menor perda do produto armazenado, possibilitando também a redução dos custos de possíveis reparos necessários.

\subsection{Análise dos resultados obtidos}

Após o protótipo ser colocado em funcionamento, foram obtidos resultados satisfatórios em relação à régua de medição convencional, indicando como principais benefícios: aumento da precisão do resultado do mensurando; devido à eliminação da margem de erro de 2,5\% da tabela de conversão do tanque, e da possibilidade de erros observacionais do operador. Verificou-se a redução das emissões de benzeno ao ambiente externo; por conta da não abertura da tampa do tanque durante a medição. Também foi percebida a redução do tempo demandado na realização das medições, e a possibilidade de mitigar desvios, furtos e vazamentos do produto; devido à funcionalidade de alertas de variação de volume, com limite de variação de $0,02 \%$ sobre o total do produto.

\section{CONSIDERAÇÕES FINAIS}

Aliado à parte econômica, o projeto foi pensado para uma atuação mais eficiente no que tange a gestão de inventário, gerando um aumento na lucratividade através da redução de custos 
de implantação, otimização do tempo, redução de perdas do material armazenado, otimização do trabalho, e maior precisão durantes nas medições realizadas.

Neste artigo foi abordada a vantagem obtida ao monitorar remotamente o nível de combustível contido nos tanques de postos de abastecimento de veículos automotores, através da implantação de um sistema eletrônico, concretizando a importância de um método mais eficaz, com relevante relação custo $\mathrm{x}$ benefício, que facilite o controle e a logística do produto.

\section{REFERÊNCIAS}

AGÊNCIA NACIONAL DO PETRÓLEO. ANP. Consulta de estabelecimentos. <https://postos.anp.gov.br/consulta.asp>. Acesso em 30 de agosto de 2018.

ARXO. O sistema de monitoramento. http://www.arxo.com/blog/br/2016/07/21/como-funcionao-sistema-de-monitoramento-do-intersticio-dos-tanques-jaquetados/. 28 de fevereiro de 2018.

ASSOCIAÇÃO BRASILEIRA DE NORMAS TÉCNICAS. NBR 13784: Detecção de vazamento em postos de serviço. Armazenamento de líquidos inflamáveis e combustíveis - Seleção de métodos para deteç̧ão de vazamentos e ensaios de estanqueidade em sistemas de armazenamento subterrâneo de combustíveis (SASC). 03 de março de 2018.

ASSOCIAÇÃO BRASILEIRA DE NORMAS TÉCNICAS. NBR 13787. Armazenamento de líquidos inflamáveis e combustíveis - Procedimento de controle de estoque dos sistemas de armazenamento subterrâneo de combustíveis (SASC) . 25 de março de 2018.

BRASIL. Ministério do Meio Ambiente/ Conselho Nacional do Meio Ambiente. Resolução CONAMA 273/00. http://www.mma.gov.br/port/conama/legiabre.cfm?codlegi=271. 03 de abril 2018.

BRASIL. MINISTÉRIO DO TRABALHO E EMPREGO - MTE. NR 9 - PROGRAMA DE PREVENÇÃO DE RISCOS AMBIENTAIS, 2016. http://trabalho.gov.br/images/Documentos/SST/NR/NR09/NR-092016.pdf . 04 de abril de 2018.

CENEDCURSOS. Postos de combustíveis - contaminação de aquíferos e solos por vazamento em tanques subterrâneos. http://www.cenedcursos.com.br/meio-ambiente/postos-de-combustiveiscontaminacao-de-aquiferos/. 01 de março de 2018.

FSINDICAL. ANEXO A - NR 9. http://www.fsindical.org.br/saude-e-seguranca/anexo-a-nr-9garante-reducao-de-exposicao-ao-benzeno-em-postos-de-combustiveis. 03 de abril de 2018.

G1 - AUTO ESPORTE - Frota brasileira de veículos cresce 1,2\% em 2017, diz Sindipeças, 2018.

<https://g1.globo.com/carros/noticia/frota-brasileira-de-veiculos-cresce-12-em017-dizsindipecas.ghtml>. 24 de abril de 2018. 